\title{
Research on Corporate Social Responsibility Governance of Internet Platform Enterprises Empowered by Big Data
}

\author{
Fei Zhang ${ }^{1, a}$, Shiwei Xu ${ }^{2, b}$ \\ ${ }^{1}$ School of Management, Chongqing Technology and Business University, ChongQing, China \\ ${ }^{2}$ School of Management, Chongqing Technology and Business University, ChongQing, China
}

\begin{abstract}
Big data analysis and processing technology are developing rapidly, and the application fields have continued to expand. Internet platform enterprises have fully enjoyed the technological dividends. In terms of their social responsibility governance, new breakthroughs could be achieved through big data empowerment. Firstly, the important role of big data empowerment in enterprise management is clarified, and the paper analyzes the characteristics of Internet platform industry. Considering the complex situation Internet platform enterprises are facing up with, a big data empowerment method is proposed to take on better governance of corporate social responsibility. Then, the research presents a comprehensive theoretical framework of "The Model of Big Data Empowerment in Social Responsibility Governance of Internet platform enterprises". It reveals that, big data empowerment provides a new dimension of social responsibility governance model for Internet platform enterprises, and the rational use of big data related technologies will help companies to better fulfill their social responsibilities.
\end{abstract}

\section{Introduction}

In today's digital era, network communication technology is more developed. The applications of big data, cloud computing and artificial intelligence have brought so much opportunities and challenges for Internet platform enterprises in their achievements of higher-level innovation and development. The Internet platform enterprises produced a large amount of information along with their user transactions and other online behaviors. These information has characteristics of huge volume, low value density, diversification and high speed, hence the name "big data". By combining data analyzing processes with data mining and other technical operations, intangible data resources could be transformed into economic value. Obviously, the rapidly rising Internet platform enterprises are favored by the market and investors.

However, during the development of Internet platform enterprises, a series of problems related to the lack of social responsibility are exposed quite often, which causes widely public discussion. For example, is the data security on Internet platform properly guaranteed? Is there a loophole in the system that can be easily exploited by criminals since some policies are not so perfect? Some of data related to user's privacy are automatically obtained by the platform's algorithms or programs. Is it against ethics? How to effectively control the phenomenon of "big data killing", which provides the same goods or services with different pricing? If such incidents are not handled in an reasonable way, it not only harms the immediate interests of each user, but also damages the corporate's social reputation. It can be inferred that under the big data environment, the subject of how Internet platform enterprises could better fulfill social responsibility is worthy of further study.

\section{Related Concepts and Theories}

\subsection{Data Empowerment and Internet Platform Enterprises}

The concept of "empowerment" was originally used in the field of human resource management. It indicates that superiors give power to improve employee capabilities and inspire others to have a more active sense of work participation ${ }^{[1]}$. In recent years, the concept of empowerment has been used more widely, and new forms such as "new retail empowerment", "technology empowerment", "IP empowerment", "traffic empowerment" have already emerged. Among them, big data empowerment is a hot spot of concern in the business circles. Data empowerment is a means of integrating the use of big data resources to effectively drive innovation in business and social management, and brings about effect of reform in both consumption and other fields. Data empowerment not only connects intelligent products and services, but also performs certain analysis and calculation on large amounts of data to obtain valuable information which would further exert huge effect in the practical stage.

azfbestec@163.com; ${ }^{b}$ Corresponding Author: xsw@ctbu.edu.cn 
Internet platform enterprises are usually operated with clear arrangement of value propositions, core resources and capability, critical businesses, pricing and services as well as profit pattern. Although scholars have different perceptions of Internet platform enterprises, they generally agree that Internet platforms have the characteristics of two-sided markets. The participants mainly include two or above groups, and other stakeholders $^{[2]}$. Compared with traditional companies, Internet platform enterprises have richer sources of income. In addition to advertising, there are also channels for profit such as membership payments. Some scholars even established economic models on the basis of two-sided markets theory to calculate the optimal amount of membership payments. Programs like this are conducted to maximize benefits of the platform enterprises. What cannot be neglected is that the benefits of network externality are prominent. That is to say, in network environment, users on one side will be significantly affected by the performance of some indicators, for example, the number of users on the other side. At the same time, Internet platform enterprises provide an open environment system in which all the parties interact with each other. Currently, most of the familiar platform enterprises are engaged in online commodity trading, supply and demand information release, resource service intermediation and other activities. The forms usually include providing virtual markets, establishing online communities, and expanding various functions based on software or application to meet user needs. Research indicates that the development and growth of any Internet platform enterprises is inseparable from extensive user resources $^{[3]}$. Therefore, the key to platform operation is to maintain the relationship between the platform and different user groups.

\subsection{The Connotation of Corporate Social Responsibility in the Platform Scenario}

Since Oliver Sheldon put forward the theory of corporate social responsibility in the year 1924, a large number of scholars have studied the issue of undertaking social responsibility in corporate management. The pyramid of corporate social responsibility, the stakeholder theory and other theories impel managers to pay attention to groups and individuals related to corporate development. Social responsibility emphasizes that in pursuing of economic benefits, operators must protect the interests of organizations, employees, society and the ecological environment. The famous master of management, Michael E. Porter, pointed out that, in addition to the rising of operating costs in a company as well as some business restrictions, social responsibility fulfillment can be turned into opportunities, and it opens up the path for corporate innovation and strengthens competitive advantage ${ }^{[4]}$. In many foreign companies, fulfilling social responsibility has become part of corporate strategic planning.

General speaking, the stakeholders of Internet platform enterprises include shareholders, investors, sellers and buyers in the platform, the government, communities, the environment and so on. In response to the demands of different stakeholders, the platform needs to consider the implementation mode and degree in fulfilling social responsibility, so as to maintain corporate governance in a balanced and effective way. In addition to emphasizing of economic and legal responsibilities, Internet platform enterprises should assume a wider range of social responsibilities, such as protecting consumers' private data, strictly examining the qualifications of merchants, and punishing those behaviors like false propaganda or click farming. Many studies reveal that by fulfilling social responsibility, companies can obtain both measurable financial performance and non-financial performance, for examples, good reputation, brand value and social identity ${ }^{[5]}$. In other words, effective social responsibility governance will promote the company's development in the long run.

\section{Digital Governance of Internet Platform Enterprises' Corporate Social Responsibility}

\subsection{The Integration of Big Data and Platform- based Business Ecosystems}

As is known, Internet platform enterprises gather a large number of users. During the operation process, huge amount of data is generated. These data normally conform to the $4 \mathrm{~V}$ characteristics (Volume, Variety, Value and Velocity) of big data, making Internet platform enterprises naturally the owners of big data. From the perspective of practical application, data thinking brings multiple benefits to platforms ${ }^{[6]}$. A typical example is that, big data can be used for precision marketing on the basis of individual consumption $^{[7]}$. Many Internet platforms collect customer information and their consumption habits, which is stored in various structured data forms. After steps of basic processing, data mining, association analysis, cluster analysis and other procedures, user portraits are constructed out of huge volume of data. As a result, the marketing department are able to predict behavioral information of consumers, for instance, customers' buying preferences, thereby increasing the conversion rate of online product recommendations.

Meanwhile, the external environment Internet platform enterprises face has formed business ecosystems, that is, "dynamic structural systems consist of organizations or groups with certain interests relationship"[8]. The platform-based business ecosystems include core enterprises, consumers, market intermediaries, suppliers, risk bearers and competitors. The modern management theory believes that enterprises should co-evolve with the entire business ecosystems. On the basis of mutual benefit, integrity and friendship, there is coexisting relationship between competition and cooperation among stakeholders ${ }^{[9]}$.

The integration of big data and platform-based business ecosystems is an inevitable trend. Under the effects of network, the number of users and orders of a platform grows rapidly, and big data has become a 
resource, which is conducive to companies' exploring of new profit models and sources for growth. Through the integrated use of massive data and links, relevant predictions and judgments could be made, thereby reflecting the network behavior characteristics of various entities in certain business ecosystems. Furthermore, with the support of big data, cloud computing and other technical means, activities like information transmission, data exchange, resource sharing and use between members are more convenient in platform-based business ecosystems. Big data also brings many opportunities for enterprise strategic decision and collaborative innovation practically.

\subsection{Solutions for Big Data Empowerment of Internet Platform Enterprises' Social Responsibility Governance}

Under the supervision of big data technology, the behavior of Internet platform enterprises is transparent, and all stakeholders can fully perceive the external social responsibility performance and internal corporate values of the platform. Therefore, it is feasible to make full use of big data empowerment to create a new model of corporate social responsibility governance for Internet platform enterprises.

On the one hand, the establishment of a social responsibility information sharing platform can be promoted in practice. Using trust mechanisms could, to some extent, give full play to the role of big data supervision and promote the fulfillment of social responsibilities among member companies in the business ecosystem. As main participants, Internet platform enterprises should play a leading role, and promote the co-governance and sharing of social responsibility information. The platforms should also encourage member companies to cooperate with each other, supervise their behavior in social responsibility governance to gain progress and development together. For enterprises revealing a lack of social responsibility, members should correct them in time to achieve a balanced operation of the entire ecosystem.

On the other hand, Internet platform enterprises should pay more attention to social responsibility information disclosure. Nowadays, network software and hardware facilities are gradually improved, and computers are able to perform management integration operations on huge volume of data. In the era of big data, the degree of open database implement and data sharing is increasing ${ }^{[10]}$, and corporate decisions must take into account the performance of social responsibility. While the platforms are pursuing economic benefits, disclosing legal and compliant social responsibility related information is necessary, which also helps meet the requirements of information use for stakeholders. The use of big data technology can improve the ability of stakeholders to identify and analyze the quality of social responsibility information disclosure and help them make decisions. Besides, Internet platform enterprises should fairly view the evaluation and rating of corporate social responsibility reports by some authoritative organizations, and accept the supervision of all sectors of the society with an open mind.

\subsection{Comprehensive Theoretical Framework}

The application fields of big data analysis and processing technology are constantly expanding, and industry scales are experiencing enlargement, all these pours new vitality into the development of platform-based businesses. Internet platform enterprises face a more complex business ecosystem and need to properly handle their relationships with stakeholders. In the process of fulfilling social responsibilities, governance innovation could be carried out by means of big data empowerment. Therefore, the paper presents a comprehensive theoretical framework named "The Model of Big Data Empowerment in Social Responsibility Governance of Internet Platform Enterprises", as shown in Figure 1.

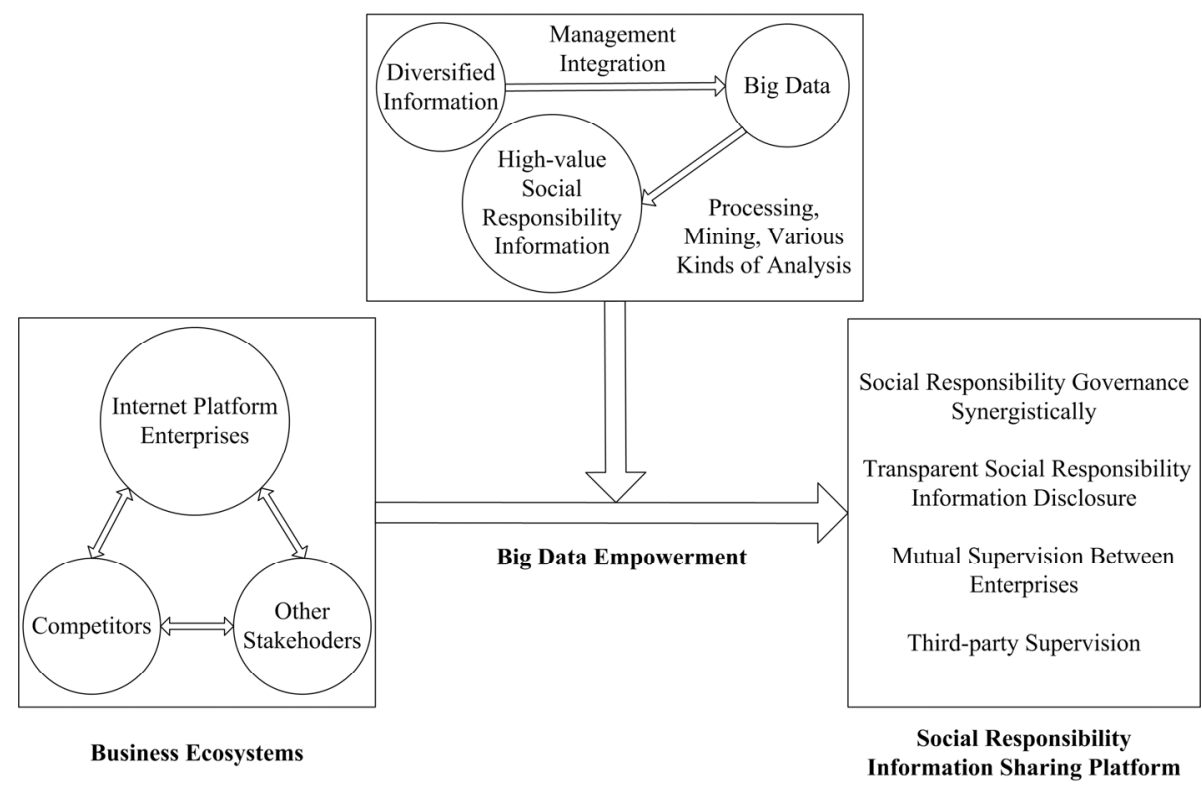

Figure 1. The Model of Big Data Empowerment in Social Responsibility Governance of Internet Platform Enterprises 
Internet platforms are seeking for development under the environment of complex business ecosystems. Most of the Internet platform enterprises naturally own massive amounts of data, which is a great advantage. After diversified information is collected and stored, it is normally presented in the form of data. By procedures of batch processing, data mining, as well as various analysis operations, these data can produce high-value social responsibility information that is beneficial to corporate management. The information shows the network behavior characteristics of enterprises and other related entities, which could be served for social responsibility governance. Then Internet platform enterprises could accordingly establish a social responsibility information sharing platform, and advocate transparent information disclosure. By strengthening mutual supervision with other enterprises, the promoting of synergy effect in social responsibility governance will be more efficient. Moreover, third-party supervision by the government and other administrative departments can also urge enterprises to undertake social responsibility seriously.

\section{Conclusion}

As discussed above, the governance model of corporate social responsibility in the platform scenario needs innovation, and big data empowerment provides a new dimension of corporate social responsibility governance. The rational use of big data resources and some technological skills will play an important role in promoting the social responsibility governance of Internet platform enterprises. The research also brings several enlightenments to Internet platform enterprises.

Firstly, Internet platform enterprises should definite their position in business ecosystems. By interacting and collaborating with other entities, they could actively participate in the construction of a healthy business ecosystem. Secondly, enterprises should reasonably use advanced digital information processing technology represented by big data, so as to enhance the value of the platform through data empowerment. The work is well worth doing since it optimizes the allocation of various resources. In the meantime, the platforms should assume moral, legal, social and environmental responsibilities to all stakeholders. Thirdly, enterprises engaged in platform operations must legally and compliantly disclose relevant information of the company, accept supervision from both the government and the public, and strengthen industry self-discipline at the same time. Multiple methods will successfully impel Internet platform enterprises to merge into the social responsibility governance structure in the era of big data in an active approach.

\section{References}

1. Johny T. Garner, 2017. Empowerment. The International Encyclopedia of Organizational Communication, pp.1-10.

2. Hałaburda, H. and Yehezkel, Y., 2013. Platform Competition under Asymmetric Information. American Economic Journal: Microeconomics, 5(3), pp.22-68.

3. Choudary P., Alstyne V. and Parker G., 2016. Platform revolution: How networked markets are transforming the economy--and how to make them work for you. W. W. Norton \& Company,

4. Porter,M.E. and M.R.Kramer., 2006. The Link Between Competitive Advantage and Corporate Social Responsibility.Harvard Business Review, 84(1-2), pp.78-92.

5. Lee, J. and Lee, Y., 2018. Effects of multi-brand company's CSR activities on purchase intention through a mediating role of corporate image and brand image. Journal of Fashion Marketing and Management: An International Journal, 22(3), pp.387-403.

6. Yuan, H., Xu, W., Li, Q. and Lau, R., 2017. Topic sentiment mining for sales performance prediction in e-commerce. Annals of Operations Research, 270(1-2), pp.553-576.

7. Yan, L., 2017. Personalized Recommendation Method for E-Commerce Platform Based on Data Mining Technology. 2017 International Conference on Smart Grid and Electrical Automation (ICSGEA),

8. Moore J F. ,1993. Predators and prey:A new ecology of competition.Harvard Business Review, 71(3):75-83

9. Liu, S. and Wu, D., 2016. Competing by conducting good deeds: The peer effect of corporate social responsibility. Finance Research Letters, 16, pp.4754.

10. Jetzek, T., Avital, M. and Bjørn-Andersen, N., 2014. Generating Sustainable Value from Open Data in a Sharing Society. Creating Value for All Through IT, pp.62-82. 